\title{
Advancements in the Growth and Construction of Recombinant Lumpy Skin Disease Virus (LSDV) for Use as a Vaccine Vector
}

\author{
Michiel van Diepen ${ }^{1,2}$, Rosamund Chapman ${ }^{1,2} \mathbb{C}^{-}$, Nicola Douglass ${ }^{1,2}, * \mathbb{D}$, Leah Whittle ${ }^{1,2}$, Nicole Chineka ${ }^{1,2}$, \\ Shireen Galant ${ }^{1,2}$, Christian Cotchobos ${ }^{1,2}$, Akiko Suzuki ${ }^{1,2} \mathbb{D}$ and Anna-Lise Williamson ${ }^{1,2, *} \mathbb{C}$ \\ 1 Department of Pathology, Division of Medical Virology, Faculty of Health Sciences, University of Cape Town, \\ Cape Town 7925, South Africa; michiel.vandiepen@uct.ac.za (M.v.D.); ros.chapman@uct.ac.za (R.C.); \\ whtlea002@myuct.ac.za (L.W.); chnane006@myuct.ac.za (N.C.); shireen.galant@uct.ac.za (S.G.); \\ ctcchr001@myuct.ac.za (C.C.); SZKAKI001@myuct.ac.za (A.S.) \\ 2 Institute of Infectious Disease and Molecular Medicine, University of Cape Town, \\ Cape Town 7925, South Africa \\ * Correspondence: Niki.Douglass@uct.ac.za (N.D.); Anna-Lise.Williamson@uct.ac.za (A.-L.W.); \\ Tel.: +27-832310553 (N.D.)
}

check for updates

Citation: van Diepen, M.; Chapman, R.; Douglass, N.; Whittle, L.; Chineka,

N.; Galant, S.; Cotchobos, C.; Suzuki,

A.; Williamson, A.-L. Advancements

in the Growth and Construction of Recombinant Lumpy Skin Disease Virus (LSDV) for Use as a Vaccine Vector. Vaccines 2021, 9, 1131. https://doi.org/10.3390/vaccines 9101131

Academic Editor: Eeva Tuppurainen

Received: 8 September 2021

Accepted: 29 September 2021

Published: 4 October 2021

Publisher's Note: MDPI stays neutral with regard to jurisdictional claims in published maps and institutional affiliations.

Copyright: (c) 2021 by the authors. Licensee MDPI, Basel, Switzerland. This article is an open access article distributed under the terms and conditions of the Creative Commons Attribution (CC BY) license (https:/ / creativecommons.org/licenses/by/ $4.0 /)$.

\begin{abstract}
Attenuated vaccine strains of lumpy skin disease virus (LSDV) have become increasingly popular as recombinant vaccine vectors, to target both LSDV, as well as other pathogens, including human infectious agents. Historically, these vaccine strains and recombinants were generated in primary (lamb) testis (LT) cells, Madin-Darby bovine kidney (MDBK) cells or in eggs. Growth in eggs is a laborious process, the use of primary cells has the potential to introduce pathogens and MDBK cells are known to harbor bovine viral diarrhea virus (BVDV). In this study, data is presented to show the growth of an attenuated LSDV strain in baby hamster kidney (BHK-21) cells. Subsequently, a recombinant LSDV vaccine was generated in BHK-21 cells. Partial growth was also observed in rabbit kidney cells (RK13), but only when the vaccinia virus host range gene K1L was expressed. Despite the limited growth, the expression of K1L was enough to serve as a positive selection marker for the generation of recombinant LSDV vaccines in RK13 cells. The simplification of generating (recombinant) LSDV vaccines shown here should increase the interest for this platform for future livestock vaccine development and, with BHK-21 cells approved for current good manufacturing practice, this can be expanded to human vaccines as well.
\end{abstract}

Keywords: lumpy skin disease virus; vaccine vector; BHK-21 cells; RK13 cells; K1L host range

\section{Introduction}

Poxviruses have a long history of being used as vectors for recombinant vaccines [1,2] Most of the registered recombinant poxvirus vaccines are for veterinary use and include the canarypox virus (CNPV) based vector ALVAC for diseases such as rabies, feline leukaemia virus and equine influenza [3-5]. Due to their safety profiles, the majority of poxviruses being explored for human use do not complete their replication cycle in humans and include canarypox virus, various vaccinia virus strains and lumpy skin disease virus (LSDV) [6-10]. Recently, the first human vaccine based on a recombinant poxvirus was approved by regulatory bodies for Ebola [11]. This vaccine is based on modified vaccinia Ankara (MVA), which does not complete its replication cycle in human cells. The vaccine encodes glycoproteins of Ebola virus Zaire, Sudan virus and Marburg virus and the nucleoprotein of the Thai Forest virus. It is given as a boost in a heterologous Ebola vaccination regimen with an Adenovirus vectored priming vaccine.

Combinations of different poxvirus vectored vaccines can give different types of immune response. In rhesus macaques, there were different systemic proinflammatory and antiviral cytokine and chemokine levels following vaccination with the canarypox virus vector, ALVAC, compared to the vaccinia virus (VACV)-derived vectors MVA and NYVAC [12]. Rhesus macaques, vaccinated in a heterologous prime boost regimen consisting 
of a recombinant modified vaccinia virus Ankara (rMVA) prime/recombinant fowlpox virus (rFPV) boost or recombinant vaccinia virus prime/rFPV boost, developed comparable cellular immune responses, which were greater in magnitude than those developed in animals that received homologous prime/boost with rMVA [13]. On testing candidate HIV-1 vaccines, heterologous prime boost with rMVA and rLSDV expressing HIV-1 antigens gave a better $\mathrm{T}$ cell response than either viral vector alone [9].

LSDV is a member of the Capripoxvirinae genus of the Poxviridae family [14] and has a host range restricted to ruminants. LSDV causes serious disease in cattle and there are effective attenuated and inactivated vaccines available $[15,16]$. Recombinant LSDV vaccines that have been tested in cattle or sheep include dual vaccines against LSDV + rabies [17] and LSDV + rift valley fever virus [18]. Pre-clinical studies of LSDV as an HIV vaccine have also taken place $[9,10]$. The promising immune responses to LSDV in replication-restricted hosts have supported the development of LSDV as a vaccine for humans [19,20]. However, the present manufacture of vaccines takes place in cell lines or primary cultures [21,22], which are not suitable for the manufacturing of human vaccines according to current good manufacturing practice. Madin-Darby bovine kidney (MDBK) cells can be used for culture in veterinary use, but this cell line is often contaminated with bovine viral diarrhea virus (BVDV). Passaging through embryonated chicken eggs can be used to remove this BVDV [23], but eggs are not considered a viable alternative for manufacture of vaccine. Recently, it was reported that Capripoxviruses grow well in cultures of the embryonic skin of sheep (ESH-L) and primary foetal heart cells, but to a lesser extent in Vero cells and an ovine testis cell line [21]. One of the aims of our study was to determine if the manufacture of LSDV could be done in a baby hamster kidney cell line (BHK-21), which is suitable for vaccine manufacture for human vaccines. An investigation was made into the construction of recombinant LSDV in BHK-21 cells. Based on the function of VACV C6 protein as a multifunctional interferon (IFN) antagonist responsible for proteasomal degradation of class II histone deacetylase 4 and 5 (HDAC4, HDAC5), with both HDACs inhibiting VACV replication in vitro $[24,25]$, it was hypothesized that the HDAC inhibitor, sodium butyrate, could impact on the growth of LSDV in BHK-21 cells.

Host range genes have implications for both growing poxviruses in vitro and for generating recombinant vaccines. The K1L gene, when recombined into MVA, enabled the rMVA to grow in cell lines outside of its normal host range [26,27]. K1L has been shown to inhibit Nuclear Factor kappa B (NF-kB) by preventing the degradation of $I k B \alpha$, a known inhibitor of NF-kB [28,29]. NF-kB is a small group of inducible transcription factors that regulate DNA transcription, cytokine production, and cellular survival. Inhibition of NF-kB thus results in impaired proinflammatory gene expression by the host [30]. The inclusion of the K1L gene into transfer vectors has likewise facilitated the selection of recombinant MVA, as recombinants expressing K1L grown in rabbit kidney (RK) 13 cells, whilst the wild-type MVA does not [27]. Additionally, following transfection with K1L and antibiotic selection to generate a stable cell line expressing K1L, RK13 cells were seen to be permissive to MVA [31]. Similar to MVA, LSDV lacks the K1L gene [32] and is thus incapable of replicating in RK13 cells. One of the aims of this research was to evaluate the growth of LSDV in the presence of K1L in the RK13 cell line, which is not normally permissive to LSDV.

The purpose of this study was to investigate ways to improve the growth and selection of recombinants of LSDV for both human and veterinary applications. LSDV was shown to grow in BHK-21 cells and K1L was shown to rescue growth of LSDV in RK13 cells.

\section{Materials and Methods}

\subsection{Antibodies, Plasmids, Cell Lines and Reagents}

Goat anti-HIV-1 gp160 (MRC ADP 72 408/5104), rabbit anti-HIV-1 p24 (Gag) (ARP 432), mouse mAb THE ${ }^{\mathrm{TM}}$ DYKDDDDK Tag Antibody for detection of the FLAG-tag (GenScript, Piscataway, New Jersey, United States, A00187), donkey anti-goat IgG FITC, donkey anti-rabbit IgG FITC or Cy3 and donkey anti-mouse IgG FITC or Cy3 (all Life Technologies, 
Carlsbad, California, USA) were used for immunofluorescence assays. Goat anti-HIV1 gp120 (BioRad, Hercules, California, United States 5000-0557), goat anti-HIV-1 p24 (Gag) (BioRad 4999-9007), THE ${ }^{\mathrm{TM}}$ DYKDDDDK Tag Antibody, mouse monoclonal antigoat/sheep IgG-AP GT34 (Sigma, St. Louis, Missouri, United States) and Goat Anti-Mouse IgG Antibody (H\&L) [Alkaline phosphatase] (GenScript, Piscataway, New Jersey, United States, A10097) were used for western blotting. MDBK, RK13, HEK293T and BHK-21 cell lines were obtained from the American Type Culture Collection (ATCC, Manassas, Virginia, United States). All cells were grown in Dulbecco's Modified Eagle's Medium (DMEM) High Glucose + L-Glutamine + 10\% Fetal Calf Serum (FCS) + 1x Pen/Strep (all Gibco, Carlsbad, California, United States). For serum-free media, no FCS was added. Recombinant LSDV was titrated in MDBK cells by counting fluorescent foci three days post infection to determine fluorescent forming units $/ \mathrm{mL}(\mathrm{FFU} / \mathrm{mL})$.

The mammalian expression plasmid pTHpCapR [33] was used as a backbone for mammalian expression plasmids and pUC57simple (GenScript) was used as a backbone for pox transfer vectors. The recombinant nLSDVSODis-UCT and modified vaccinia Ankara (MVA) that expresses HIV-1 CAP256 Env + subtype C mosaic Gag (MVAGC5) have been previously described $[34,35]$. The construction of LSDVGC5 is described by Chapman et al. (in the concurrent special issue of Vaccines). LSDVGC5 expresses HIV-1 CAP256 Env + subtype C mosaic Gag [35].

All imaging was performed on a Zeiss Axio Microscope (Carl Zeiss AG, Oberkochen, Germany) and analysed with Zeiss Zen software (https: / / www.zeiss.com/microscopy / int/products/microscope-software/zen-lite.html (accessed on 4 October 2021)).

All graphs were plotted in GraphPad Prism 5.0 (GraphPad Software, San Diego, CA, United States).

\subsection{Promoter Activity in LSDV}

Five promoters were tested for recognition by LSDV. These are shown in Table 1 and include a synthetic early-late promoter of VACV (pSS) [36], a synthetic early-late optimised promoter of VACV (pLEO)[37], a modified early fowlpox virus promoter (pmFP), which had the late portion of the promoter removed [38,39], a promoter of the 7.5 kilo Dalton ( $\mathrm{kDa})$ polypeptide gene of VACV ( $\mathrm{p} 7.5$ ) [40] and a modified early-late promoter of the H5 gene of VACV (pmH5) [41]. Each promoter was cloned upstream of eGFP in pUC57simple and tested for transient expression, after transfection of BHK-21 cells, which were infected with nLSDVSODis-UCT. A 70\% confluent layer of BHK-21 cells, in 12-well plates, were infected with LSDV $(\mathrm{MOI}=0.5)$ and $2 \mathrm{~h}$ later transfected with $2 \mu \mathrm{g}$ of the respective VACV promoter-eGFP plasmids using $1 \mu \mathrm{L}$ of X-tremeGENE HP ( Roche, Basel, Switzerland). The eGFP signal was imaged as a proxy for VACV promoter activity two days after transfection.

Table 1. Poxvirus promoter sequences.

\begin{tabular}{|c|c|c|c|}
\hline Promoter & Sequence & Size & Ref \\
\hline pSS & AAAATTGAAATTTTATTTTTTTTTTTTGGAATATAAATA & $39 \mathrm{bp}$ & [36] \\
\hline pLEO & $\begin{array}{l}\text { TTTTATTTTTTTTTTTTGGAATATAAATATCCGGTAAAATTGAAAAAATATACAC } \\
\text { TAATTAGCGTCTCGTTTCAGACGCTAG }\end{array}$ & $82 \mathrm{bp}$ & [37] \\
\hline pmFP & AGAAAAATATCCTAAAATTGAATTGTAATTATCGATAATAA & $41 \mathrm{bp}$ & {$[38,39]$} \\
\hline p7.5 & $\begin{array}{l}\text { TCCAAACCCACCCGCTTTTTATAGTAAGTTTTTCACCCATAAATAATAAA } \\
\text { TACAATAATTAATTTCTCGTAAAAGTAGAAAATATA TTCTAATTTATTGCACGG }\end{array}$ & $104 \mathrm{bp}$ & {$[40]$} \\
\hline pmH5 & $\begin{array}{l}\text { AAAAATTGAAAATAAATACAAAGGTTCTTGAGGGTTGTGTTAAATT } \\
\text { GAAAGCGAGAAATAATCATAAATAA }\end{array}$ & $71 \mathrm{bp}$ & [41] \\
\hline
\end{tabular}

\subsection{Generation of Recombinant LSDVGC5 Virus in BHK-21 Cells}

A recombinant $n L S D V S O D i s-U C T$ virus (LSDV(SODis)BEFV-Gb) containing an eGFP marker in the 49-50 locus (Douglass et al., concurrent special issue of Vaccines) was used 
to target the expression cassette of pmH5-Env, pLEO-mosaic Gag and pmFP-mCherry into the 49-50 locus, with a positive integration event marked by replacing eGFP expression with that of mCherry. A similar strategy was employed for the construction of LSDVGC5 described by Chapman et al. (in concurrent special issue of Vaccines).

BHK-21 cells were plated and infected at the same time with $1 \mu \mathrm{L}$ LSDV(SODis)BEFV$\mathrm{Gb}\left(1.8 \times 10^{7} \mathrm{TCID}_{50} / \mathrm{mL}\right)$. Two hours later, infected cells were transfected with $1 \mu \mathrm{g}$ of the transfer vector pFLEx(49-50) CAP256 gp150-FL-IP Gag ${ }^{\mathrm{M}}$ mCherry, using $1 \mu \mathrm{L}$ of X-tremeGENE HP. Cells were frozen three days post transfection for passage 0 (P0). Single clones were generated in BHK-21 cells by either picking mCherry positive foci (P1) or by limited dilution ranges of cell lysate after freeze thawing (>P1). By P4, wells containing only mCherry positive recombinant LSDV were obtained, thus generating LSDVGC5 (BHK21). Single foci were bulked up in T75, T175 and Hyperflasks using BHK-21 cells. After freeze-thawing, the virus was pelleted on a $36 \%$ sucrose cushion, reconstituted in PBS + $10 \%$ glycerol and stored at $-80^{\circ} \mathrm{C}$. Correct integration into nLSDV(SODis)BEFV-Gb was verified by PCR, and expression of Env and Gag from LSDVGC5 (BHK-21) was assessed by western blotting and immunofluorescence.

\subsection{Growth Curve of LSDVGC5 in BHK-21 Cells}

BHK-21 cells were infected with LSDVGC5 at MOI $=0.05$ in triplicate $(n=3)$ with or without the pan-HDAC inhibitor $2 \mathrm{mM}$ sodium butyrate (Sigma) in 12-well plates ( $n=10$ plates). As a control LSDVGC5 was added to three wells without cells in each plate. Cells were plated and infected on the same day. Wells were imaged daily and one plate was frozen each day for downstream titration after two freeze-thaw cycles to determine FFU/mL. This data was Log10 converted, plotted and analysed in GraphPad Prism 5.0.

\subsection{Transgene Expression from MVAGC5 and LSDVGC5 in Non-Permissive Cells Stimulated with the pan-HDAC Inhibitor Sodium Butyrate}

HEK293T cells were infected with MVAGC5 or LSDVGC5 at MOI = 0.5 in triplicate $(n=3)$ with or without the pan-HDAC inhibitor $2 \mathrm{mM}$ sodium butyrate in 12-well plates ( $n=4$ plates). Cells were plated and infected on the same day. After three days, media was removed from one plate and cells were lysed with $500 \mu \mathrm{L}$ Glo Lysis buffer (Promega, Madison, Wisconsin, United States). Equal volumes of cell lysate were run on protein SDS PAGE and expression of the MVAGC5 and LSDVGC5 transgene HIV-1 Env was confirmed by western blot analysis, imaged on a BioRad GelDoc XR, with densitometry performed with the accompanying ImageLab software (BioRad, Hercules, California, United States).

\subsection{Generation of RK13 Cells with Stable Expression of VACV K1L}

The VACV host-range gene K1L was PCR cloned into pTHpCapR to include a short C-terminal linker (GGGGS) and FLAG-tag (DYKDDDDK) upstream of the STOP codon, thereby generating the plasmid pMEx K1L-FLAG. The K1L gene was verified by DNA sequencing. Subsequently, an IRES-Neomycin resistance cassette was introduced directly downstream of K1L-FLAG to generate pMEx K1L-FLAG Ires Neo(r) (pMEx K1L-FLAG IN), which was used to make cell lines stably expressing K1L-FLAG. Transient expression in RK13 cells of K1L-FLAG from pMEx K1L-FLAG and pMEx K1L-FLAG-IN was verified by western blot analysis and immunofluorescence using the FLAG-tag. RK13 cells with stable expression of K1L-FLAG were generated by transfecting with pMEx K1L-FLAG-IN and passaging cells for $>10$ passages in media $+0.5 \mathrm{mg} / \mathrm{mL}$ Geneticin (Gibco). For this cell line, RK13 K1L, expression of K1L-FLAG was verified by western blot analysis and immunofluorescence. A subsequent clonal cell line, with detectable expression of K1L in all cells, as assessed by immunofluorescence, was identified by screening single clones from limited dilution ranges of RK13 K1L, thus generating RK13-K1L(H10). 


\subsection{LSDVGC5 Growth in RK13 Cells}

LSDV titration experiments were performed in the RK13-K1L(H10) cell line. Cells were infected with LSDVGC5 $(\mathrm{MOI}=0.3)(n=3)$ and, after three days, virus was harvested by freeze-thawing and titrated in MDBK cells.

\subsection{Generation of LSDV-K1L-eGFP in RK13 Cells}

A recombinant LSDV, LSDV(SODis)BEFV-Ga, containing a mCherry marker in the 49-50 locus (Douglass et al., concurrent special issue of vaccines) was used to target a construct containing the VACV host-range gene K1L under its native promoter and pSS-eGFP into the 49-50 locus, with a positive integration event marked by replacing mCherry expression with eGFP. In this case, one day after plating, primary LT cells were infected with LSDV(SODis)BEFV-Ga and two hours later transfected with the transfer vector pLSDV-K1L-eGFP ( $5 \mu \mathrm{g}$, linearised with XhoI and BamHI, followed by heat inactivation) using $3 \mu \mathrm{L}$ X-tremeGENE HP. Cells were frozen two days post transfection for P0. Viral lysates were generated by freeze-thawing and used for passaging in RK13 cells. From P2 onwards, mCherry and eGFP positive foci in RK13 cells were counted. By P4, wells containing only eGFP positive recombinant LSDV were observed. Correct integration into LSDV(SODis)BEFV-Ga to produce LSDV-K1L-eGFP was verified by PCR. Clonal LSDV-K1L-eGFP generated in RK13 cells was further bulked-up in BHK-21 cells.

\section{Results}

\subsection{Expression of Foreign Genes by LSDV from Different Promoters}

Poxviruses use specific promoters for expression, with VACV promoters being the best characterised [42]. The activity of previously characterized poxvirus promoters, placed upstream of a GFP reporter gene, were tested in transient expression assays in LSDVinfected cells to determine if they would be recognized by LSDV. All five promoters, namely pSS, pLEO, pmFP, p7.5 and pmH5, were active in combination with LSDV (Figure 1). In the absence of LSDV infection, no eGFP expression was seen from cells transfected with the reporter plasmids.
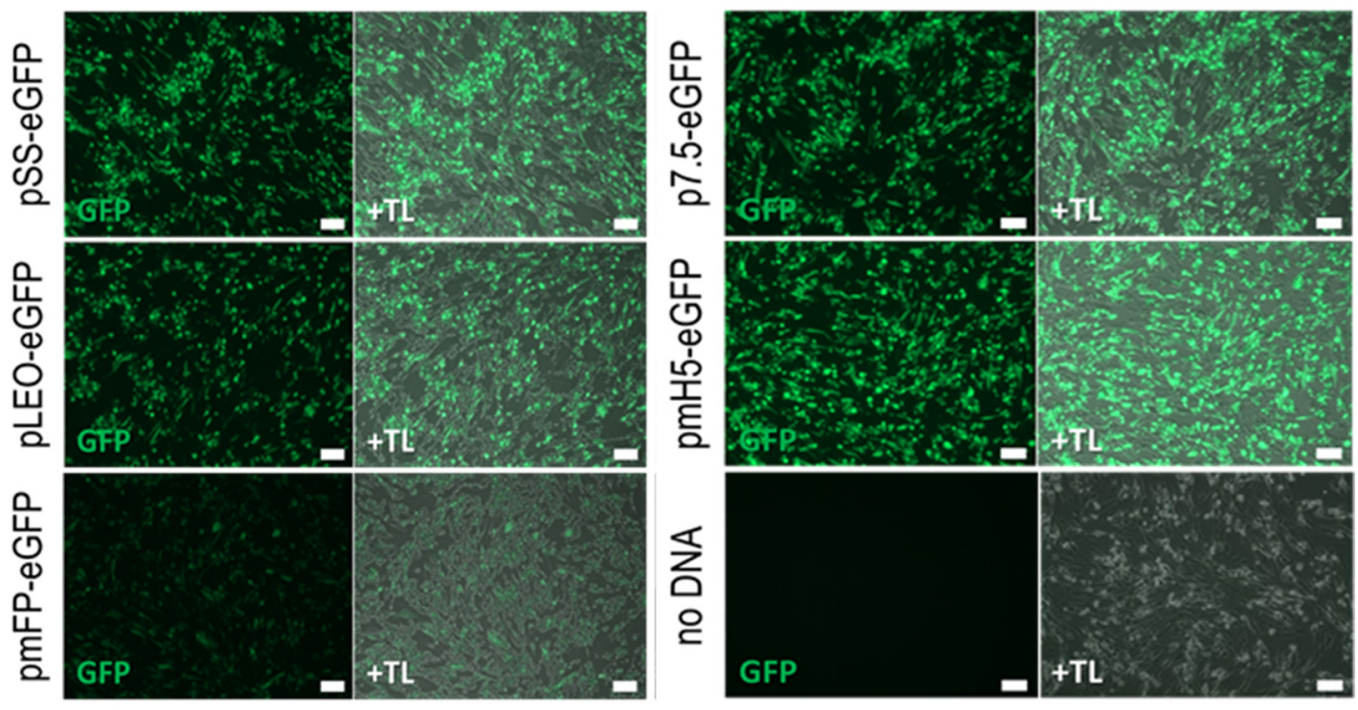

Figure 1. Expression of eGFP from different promoters in LSDV-infected BHK-21 cells. BHK-21 cells were infected with nLSDVSODis-UCT at an MOI of 0.5 and transfected with 2 ug plasmid, encoding the eGFP gene driven by poxvirus promoters pSS, pLEO, pmFP, p7.5 or pmH5. Images were taken two days post infection using green fluorescence (GFP) and phase contrast merged with green fluorescence $(+\mathrm{TL}) \cdot \mathrm{pSS}=$ synthetic vaccinia virus promoter, $\mathrm{pLEO}=$ synthetic late-early promoter, $\mathrm{pmFP}=$ fowlpox virus promoter modified to remove late promoter element, $\mathrm{p} 7.5=$ vaccinia virus $7.5 \mathrm{kDa}$ promoter, $\mathrm{pmH} 5=$ modified vaccinia virus H5 promoter. Scale bar $=100 \mu \mathrm{m}$. 


\subsection{Construction of Recombinant LSDVGC5 in BHK-21 Cells}

Recombinant LSDV, expressing HIV-1 env and gag genes, together with mCherry as a fluorescent marker, was constructed (Figure 2). Single LSDVGC5 clones were generated in BHK-21 cells by picking mCherry positive foci (passage (P) 1) followed by limited dilution ranges of virus supernatant after freeze thawing $(>\mathrm{P} 1)$. By $\mathrm{P} 4$, wells containing only mCherry positive recombinant LSDV were obtained, thus generating LSDVGC5 (BHK-21).

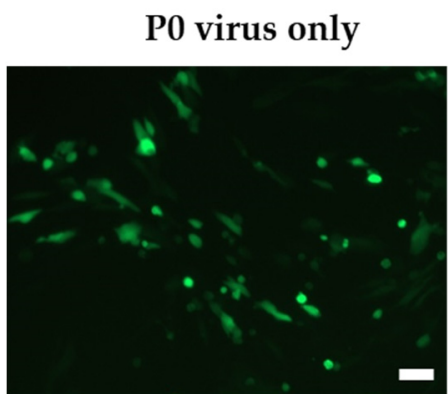

$$
\text { P0 virus + plasmid DNA }
$$

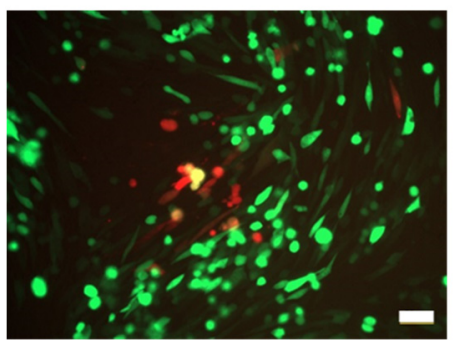

P1
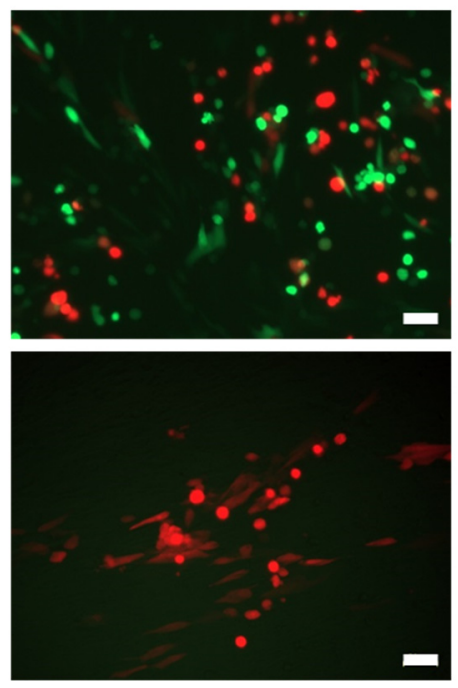

P4

Figure 2. Generation of recombinant LSDVGC5 in BHK-21 cells from the parent LSDV(SODis)BEFVGb expressing eGFP. Plasmid DNA = transfer vector containing mCherry marker. $\mathrm{P} 0=$ initial infection and transfection of BHK-21 cells, $\mathrm{P} 1=$ passage $1, \mathrm{P} 4=$ passage 4 . Scale bar $=50 \mu \mathrm{m}$.

3.3. Evaluation of the Growth of LSDV and Expression of Foreign Genes from LSDV, in BHK Cells, in the Presence and Absence of Sodium Butyrate

Growth of LSDVGC5 in BHK-21 cells was demonstrated, and this was enhanced by the addition of the pan-HDAC inhibitor sodium butyrate from days 3 to 6 post infection (Figures 3 and 4). However, by day 7 the titre was the same, whether the cells were treated with sodium butyrate or not (Figure 4). It was noted that, by this time, many of the cells treated with sodium butyrate had died.

Expression of HIV Env from recombinant poxviruses LSDVGC5 and MVAGC5 was evaluated after the addition of the pan-HDAC inhibitor sodium butyrate. This resulted in increased Env expression as observed by western blot analysis (Figure 5). 


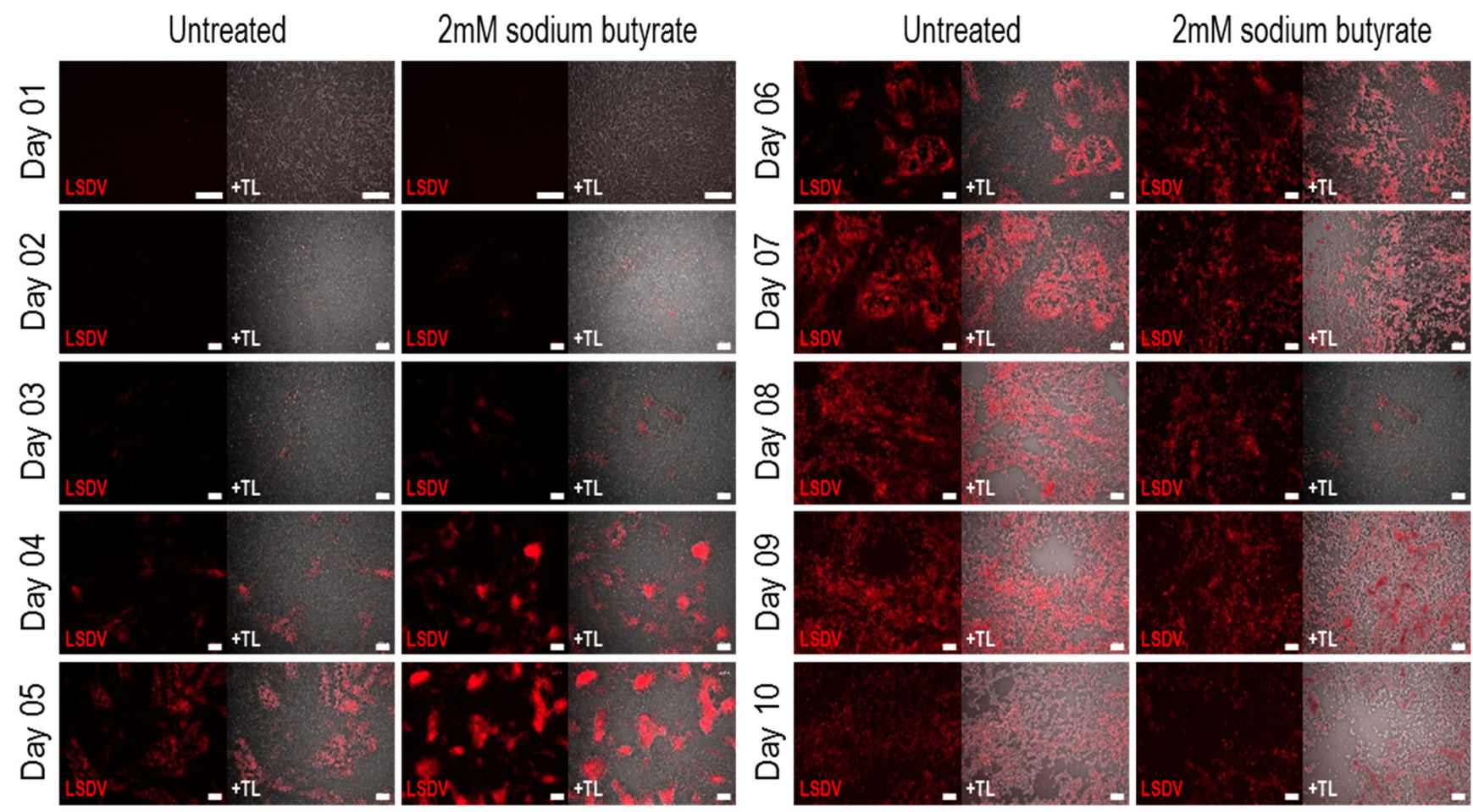

Figure 3. Growth of LSDVGC5 (expressing mCherry) in BHK-21 cells with and without sodium butyrate. Cells were infected on day 0 at $\mathrm{MOI}=0.5$. Scale bar $=200 \mu \mathrm{m}$.

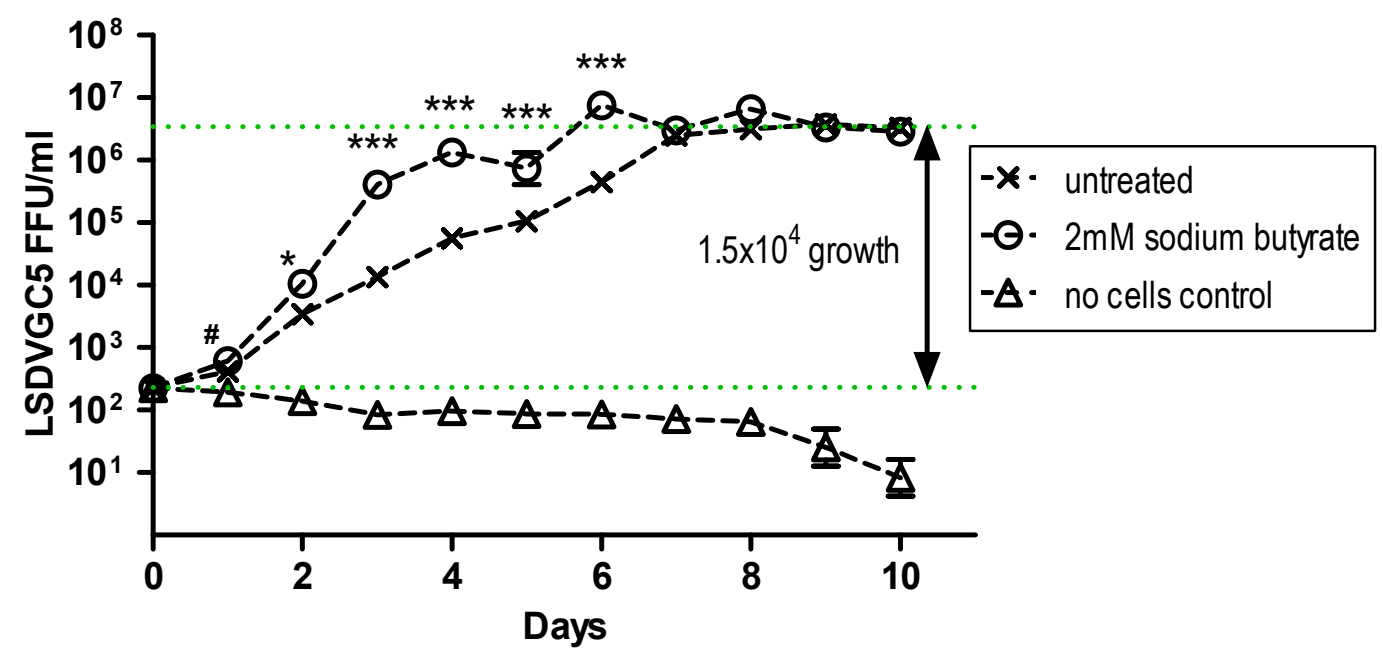

Figure 4. Growth of LSDVGC5 in BHK-21 cells in the presence and absence of sodium butyrate (SB). BHK-21 cells were infected at MOI $=0.5(n=6) .{ }^{*}{ }^{* * *}$ : untreated vs. SB $(p<0.05$ or 0.001 respectively $)$, \#: SB vs. no cells $(p<0.05)$, untreated or SB vs. no cells $(p<0.001)$ from day 2 to 10 . 


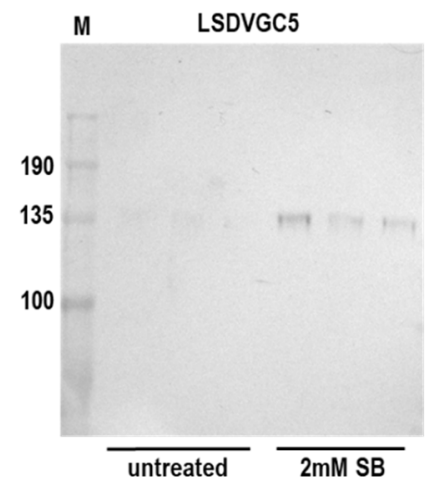

(a)

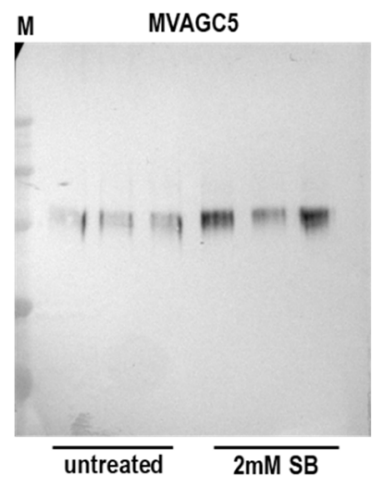

(b)

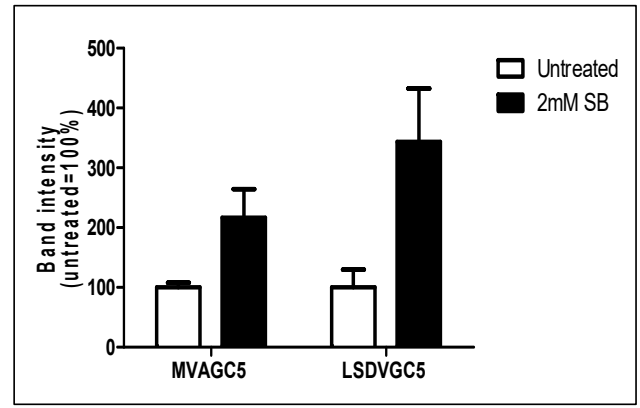

(c)

Figure 5. Expression of HIV-1 Env from nonpermissive HEK292T cells infected with LSDVGC5 or MVAGC5 in the presence and absence of $2 \mathrm{mM}$ sodium butyrate. Cell lysates were prepared in triplicate $72 \mathrm{~h}$ post infection with LSDVGC5 (a) or MVAGC5 (b) and subjected to western blot analysis. Densitometry readings were plotted using GraphPad Prism 5 (c).

\subsection{The Use of VACV K1L to Improve Growth of LSDV and Select for Recombinant LSDV}

RK13 cells are non-permissive for the growth of LSDV. A stable RK13 cell line, which expressed VACV K1L (RK13-K1L(H10)) was generated (Figure 6a). Comparison of LSDV growth in RK13 (wtRK13) and RK13-K1L(H10) cells showed a five-fold increase in the growth of LSDV in the RK13-K1L(H10) cell line (Figure 6b), confirming that K1L enabled growth of LSDV in RK13 cells.

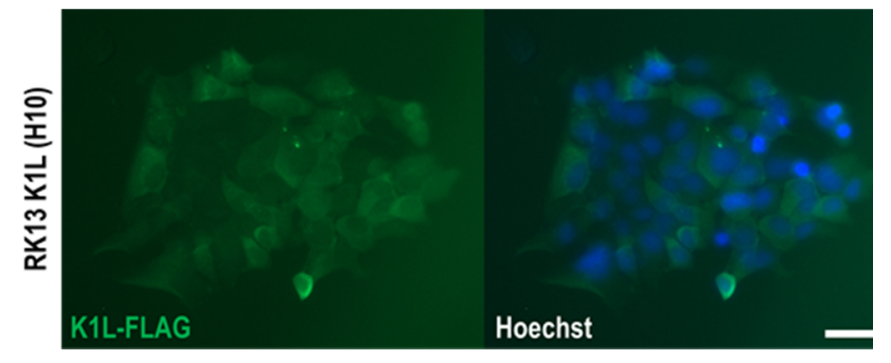

(a)

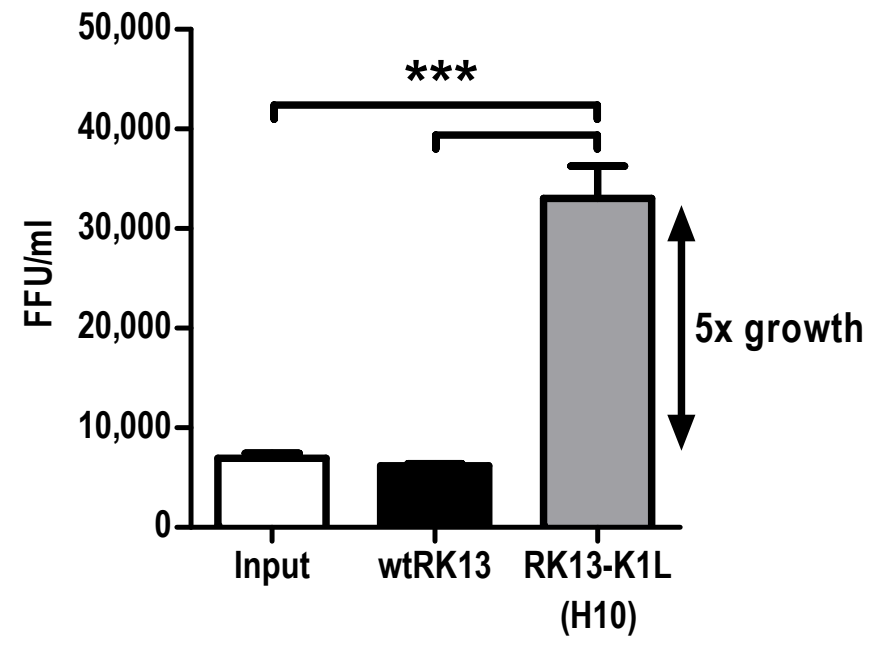

(b)

Figure 6. Generation of RK13 cells with stable expression of VACV K1L to rescue growth of LSDV. (a) Immunofluorescence showing expression of K1L by the clonal cell lineRK13-K1L(H10); K1L expression was detected by probing for the C-terminal Flag-tag present in the transgene. Scale bar $=100 \mu \mathrm{m}$. (b) Growth of LSDVGC5 in the RK13-K1L(H10) cell line as compared to wildtype RK13 three days post infection. ${ }^{* *} p<0.001$.

To determine whether K1L could be used as a means of selection in the construction of recombinant LSDV, a recombinant LSDV expressing eGFP and K1L was isolated by passage in RK13 cells. Cell lysate was used from LT cells infected with LSDV(SODis)BEFV-Ga and transfected with a transfer vector containing K1L and eGFP between flanking sequences of LSDV ORFs 49 and 50. Figure 7 shows the enrichment of green foci over red foci with passage in RK13 cells. The parent virus, which expressed mCherry, was completely replaced by recombinant LSDV-K1L-eGFP by P5. The recombinant was confirmed to be correct by PCR (Figure 7d) and Sanger sequencing of the gene cassette inserted between 
LSDV ORFs 49 and 50. This shows that K1L can be used as a means of selection for generating recombinant LSDV.

(a)

LSDV(SODis) BEFV-Ga

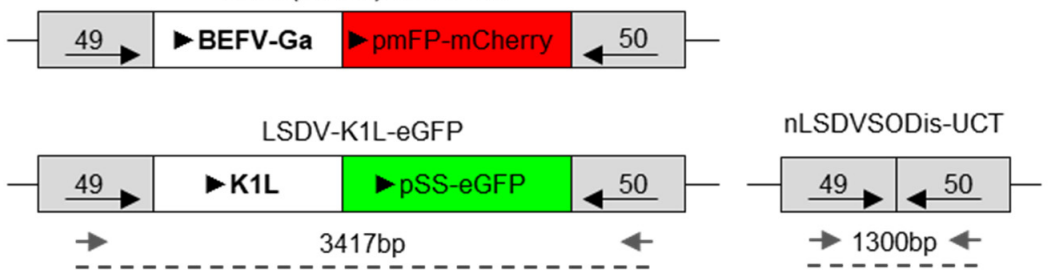

(b)

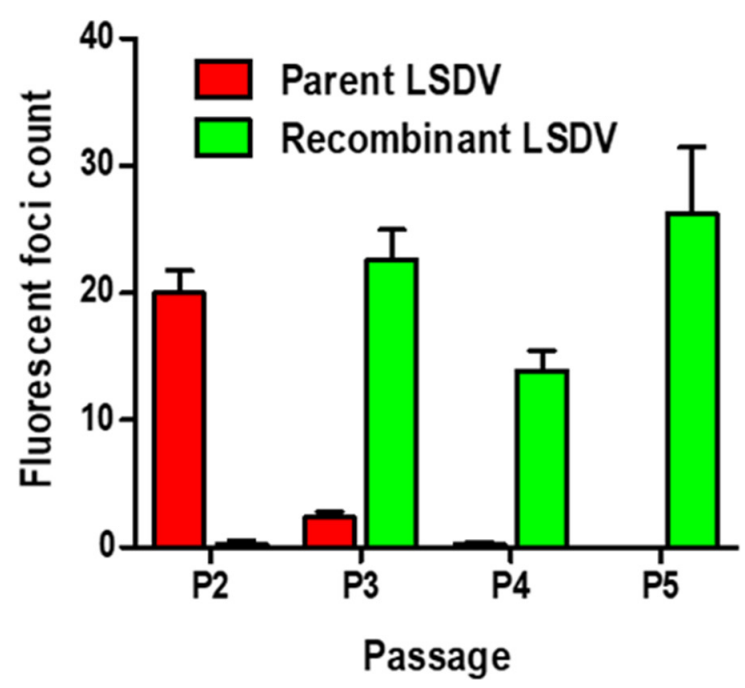

(c)

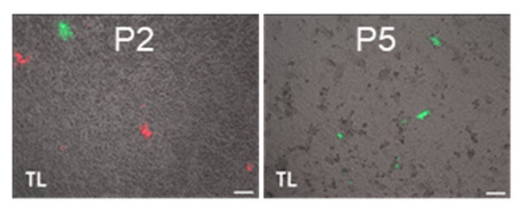

(d)

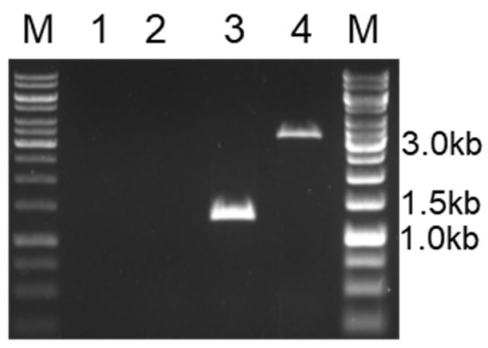

Figure 7. Generation of LSDV- K1L-eGFP in RK13 cells. (a) Schematic diagram of the parent virus, LSDV(SODis)BEFV-Ga, LSDV-K1L-eGFP and nLSDVSODis-UCT. (b) Fluorescing foci were counted as RK13 cell lysates were passaged (P2 to P5). Red and green bars indicate red and green foci counts respectively. (c) Images of passage 2 and 5 of potential LSDV-K1L-eGFP recombinant. Phase contrast with mCherry and eGFP, scale bar $=100 \mu \mathrm{m}$. (d) PCR confirmation of LSDV-K1L-eGFP. DNA was extracted from infected BHK-21 cells and subjected to PCR using forward and reverse primers (small grey arrows) as indicated in A. M-GeneRuler $1 \mathrm{~kb}$ DNA Ladder, lane 1-water control, 2-uninfected cells, 3-nLSDVSODis-UCT, 4-LSDV-K1L-eGFP.

There was no growth advantage seen in BHK-21 cells when LSDV-K1L-eGFP was compared to the parent virus (data not shown).

\section{Discussion}

Host-restricted poxviruses are important as vaccine vectors because they have numerous advantages compared to other vaccine vectors. They are heat stable and can be stored at room temperature. Poxviruses have capacity for insertion and expression of up to $25 \mathrm{kbp}$ of foreign DNA compared to adenovirus vectors where package size is limited to $7.5 \mathrm{kbps}$. They can infect a wide range of cells and express foreign proteins at levels that induce good immune responses. The fact that they replicate in the cytoplasm is another consideration as there is less likelihood of integration into the host genome [2,43-46]. LSDV has the potential to be added to the list of other poxviruses that have been successfully used in commercial human and veterinary vaccine development [20].

It is important to note that poxviruses differ in the distinct types of immune responses induced when used as vaccine vectors. Analysis of the spleen transcriptome to assess the innate immune response in mice to six host restricted poxviruses (lumpy skin disease virus (LSDV), MVA and four Avipoxviruses) demonstrated quantitatively distinct host responses. 
LSDV, followed by MVA, induced the greatest interferon (IFN) response, while CNPV and fowlpoxvirus induced the up regulation of two immunoglobulin genes (Ighg and Ighg3 (IgG3)) with CNPV inducing a third, Ighm (IgM) [47]. HIV-1-specific IgG3 antibodies have been reported to correlate with decreased risk of HIV-1 infection in the RV144 trial, which included a CNPV-based vector [48]. MVA- and LSDV- vectored HIV-1 vaccines have been shown to give superior $\mathrm{T}$ cell responses in heterologous (vs homologous) prime-boost experiments [10] and recombinant LSDV was able to significantly boost recombinant MVA primed responses in rhesus macaques [9]. Although there is evidence that MVA can be used repeatedly as a vaccine vector in the same host [49] it is expected that eventually anti-vector immunity will play a role in suppressing immune responses to boosts based on the same vector. The distinct characteristics of the various poxvirus vectors and improvements in immune responses with heterologous prime boost vaccinations justify further development of more poxvirus vectors, including LSDV.

The demonstration that LSDV can grow to relatively high titres in BHK-21 cells, and the fact that this cell line is suitable for the generation of recombinant LSDV opens the possibility of improved manufacturing processes for both human and veterinary vaccines. Confirmation of a range of VACV promoter activity increases the number of poxvirus promoters that can be used to generate recombinants. While many researchers want increased promoter activity, high-strength promoters can result in an excess of foreign protein leading to instability and selection of unstable recombinants [50]. In poxvirus vaccine design, early promoters that enhance antigen expression also improve the antigenspecific CD8 T-cell responses [51]. Our study showed that LSDV replication can be further enhanced by the addition of the pan-HDAC inhibitor sodium butyrate. Although sodium butyrate improved expression of the recombinant genes in MVA and LSDV, it is not certain whether this is due to increased poxvirus growth alone or an increase in protein expression too. An additional lever on improving foreign gene expression could be of particular interest for recombinants expressing foreign genes which may cause instability during manufacture.

Selection of poxvirus recombinants by homologous recombination is a long and laborious process and so alternatives are needed. Recent improvements have included the synthesis of horsepox virus from chemically synthesized DNA, which could be used to make recombinants [52], and the use of CRISPR/Cas9 technology to target the parent poxvirus genome [53]. Both these approaches are relatively expensive. In our study, we demonstrate that partial LSDV growth was observed in RK13 cells, but only when the VACV host gene K1L was expressed. Despite the limited growth, the expression of K1L was enough to serve as a positive selection marker for the generation of recombinant LSDV vaccines in RK13 cells. The passage of virus in RK13 cells is considerably less laborious than the standard method of picking foci. The simplification of generating (recombinant) LSDV vaccines shown here should increase the interest in this platform for future livestock vaccine development and, with BHK-21 cells approved for current good manufacturing practice, this can be expanded to human vaccines. The inclusion of K1L in LSDV did not result in improved replication in BHK-21 cells but the impact on pathogenicity in vivo, whether in non-permissive or permissive hosts, is not known and remains to be determined. Alternatively, K1L could be removed from the final recombinant, as is often done with MVA, by flanking the K1L gene with repetitive DNA sequences [27]. In MVA, the use of K1L did not enhance replication in human or monkey cell lines [54] or result in replication in rabbits [35]. LSDV is regarded as a very safe vaccine vector for non-permissive hosts as there is no evidence that the virus can replicate in non-ruminant hosts. Therefore, the risk of rescue of a replicating virulent LSDV under these circumstances is negligible. This is not the case for MVA, which, in very rare circumstances, could theoretically recombine with naturally circulating Orthopoxviruses during co-infection [44].

In conclusion, we have demonstrated that BHK-21 cells can be used to grow LSDV and to create recombinant viruses. A number of promoters used for foreign gene expression in vaccinia virus have been shown to work for LSDV too. We have also shown that K1L can 
be used for selection of recombinant LSDV in RK13 cells. These are significant advances in the quest to develop LSDV as a vaccine vector, both for animal and human use.

Author Contributions: Conceptualization, M.v.D., R.C., N.D. and A.-L.W.; Data curation, M.v.D. and R.C.; Formal analysis, M.v.D., R.C., L.W. and N.C.; Funding acquisition, A.-L.W.; Investigation, M.v.D., R.C., N.D., L.W., N.C., C.C., A.S. and A.-L.W.; Methodology, M.v.D., R.C., N.D., L.W., N.C., S.G., C.C. and A.S.; Project administration, M.v.D., R.C. and A.-L.W.; Resources, A.-L.W.; Supervision, M.v.D., R.C., N.D., L.W. and A.-L.W.; Validation, M.v.D. and R.C.; Visualization, M.v.D., R.C., L.W., N.C. and A.S.; Writing—original draft, M.v.D. and A.-L.W.; Writing—review \& editing, M.v.D., R.C., N.D. and A.-L.W. All authors have read and agreed to the published version of the manuscript.

Funding: This research was funded by the South African Medical Research Council with funds received from the South African Department of Science and Technology; A-L W is funded by the National Research Foundation of South Africa, grant number 64815 and N.D. was co-funded by the Technology Innovation Agency, project number TBS14-0020C.

Institutional Review Board Statement: Not applicable.

Informed Consent Statement: Not applicable.

Conflicts of Interest: A patent application has been filed on the LSDV vector backbones, international application number PCT/IB2019/054090 (agency reference PA166012PCT). The funders had no role in the design of the study; in the collection, analyses, or interpretation of data; in the writing of the manuscript, or in the decision to publish the results.

\section{References}

1. Tartaglia, J.; Pincus, S.; Paoletti, E. Poxvirus-based vectors as vaccine candidates. Crit Rev. Immunol. 1990, 10, 13-30. [PubMed]

2. Sanchez-Sampedro, L.; Perdiguero, B.; Mejias-Perez, E.; Garcia-Arriaza, J.; Di Pilato, M.; Esteban, M. The evolution of poxvirus vaccines. Viruses 2015, 7, 1726-1803. [CrossRef]

3. Taylor, J.; Tartaglia, J.; Riviere, M.; Duret, C.; Languet, B.; Chappuis, G.; Paoletti, E. Applications of canarypox (ALVAC) vectors in human and veterinary vaccination. Dev. Biol. Stand. 1994, 82, 131-135.

4. Jarrett, O. Efficacy of recombinant feline leukemia virus vaccines. AIDS Res. Hum. Retrovir. 1996, 12, 435-436. [CrossRef]

5. El-Hage, C.M.; Savage, C.J.; Minke, J.M.; Ficorilli, N.P.; Watson, J.; Gilkerson, J.R. Accelerated vaccination schedule provides protective levels of antibody and complete herd immunity to equine influenza. Equine Vet. J. 2013, 45, 235-239. [CrossRef]

6. Kim, J.H.; Excler, J.L.; Michael, N.L. Lessons from the RV144 Thai phase III HIV-1 vaccine trial and the search for correlates of protection. Annu. Rev. Med. 2015, 66, 423-437. [CrossRef]

7. Churchyard, G.; Mlisana, K.; Karuna, S.; Williamson, A.L.; Williamson, C.; Morris, L.; Tomaras, G.D.; De Rosa, S.C.; Gilbert, P.B.; $\mathrm{Gu}, \mathrm{N}$; ; et al. Sequential Immunization with gp140 boosts immune responses primed by modified vaccinia ankara or DNA in HIV-Uninfected South African participants. PLoS ONE 2016, 11, e0161753. [CrossRef]

8. Gray, G.E.; Mayer, K.H.; Elizaga, M.L.; Bekker, L.G.; Allen, M.; Morris, L.; Montefiori, D.; De Rosa, S.C.; Sato, A.; Gu, N.; et al. Subtype C gp140 vaccine boosts immune responses primed by the South African AIDS vaccine initiative DNA-C2 and MVA-C HIV Vaccines after More than a 2-Year Gap. Clin. Vaccine Immunol. 2016, 23, 496-506. [CrossRef]

9. Burgers, W.A.; Ginbot, Z.; Shen, Y.J.; Chege, G.K.; Soares, A.P.; Muller, T.L.; Bunjun, R.; Kiravu, A.; Munyanduki, H.; Douglass, N.; et al. The novel capripoxvirus vector lumpy skin disease virus efficiently boosts modified vaccinia Ankara human immunodeficiency virus responses in rhesus macaques. J. Gen. Virol. 2014, 95, 2267-2272. [CrossRef] [PubMed]

10. Shen, Y.J.; Shephard, E.; Douglass, N.; Johnston, N.; Adams, C.; Williamson, C.; Williamson, A.L. A novel candidate HIV vaccine vector based on the replication deficient Capripoxvirus, Lumpy skin disease virus (LSDV). Virol. J. 2011, 8, 265. [CrossRef] [PubMed]

11. Volkmann, A.; Williamson, A.L.; Weidenthaler, H.; Meyer, T.P.H.; Robertson, J.S.; Excler, J.L.; Condit, R.C.; Evans, E.; Smith, E.R.; Kim, D.; et al. The Brighton Collaboration standardized template for collection of key information for risk/benefit assessment of a Modified Vaccinia Ankara (MVA) vaccine platform. Vaccine 2021, 39, 3067-3080. [CrossRef]

12. Teigler, J.E.; Phogat, S.; Franchini, G.; Hirsch, V.M.; Michael, N.L.; Barouch, D.H. The canarypox virus vector ALVAC induces distinct cytokine responses compared to the vaccinia virus-based vectors MVA and NYVAC in rhesus monkeys. J. Virol. 2014, 88, 1809-1814. [CrossRef] [PubMed]

13. Santra, S.; Sun, Y.; Parvani, J.G.; Philippon, V.; Wyand, M.S.; Manson, K.; Gomez-Yafal, A.; Mazzara, G.; Panicali, D.; Markham, P.D.; et al. Heterologous prime/boost immunization of rhesus monkeys by using diverse poxvirus vectors. J. Virol. 2007, 81, 8563-8570. [CrossRef] [PubMed]

14. Kitching, R.P. Vaccines for lumpy skin disease, sheep pox and goat pox. Dev. Biol. 2003, 114, 161-167.

15. Haegeman, A.; De Leeuw, I.; Mostin, L.; Campe, W.V.; Aerts, L.; Venter, E.; Tuppurainen, E.; Saegerman, C.; De Clercq, K. Comparative evaluation of lumpy skin disease virus-based live attenuated vaccines. Vaccines 2021, 9, 473. [CrossRef] [PubMed] 
16. Hamdi, J.; Boumart, Z.; Daouam, S.; El Arkam, A.; Bamouh, Z.; Jazouli, M.; Tadlaoui, K.O.; Fihri, O.F.; Gavrilov, B.; El Harrak, M. Development and evaluation of an inactivated lumpy skin disease vaccine for cattle. Vet. Microbiol. 2020, 245, 108689. [CrossRef]

17. Aspden, K.; van Dijk, A.A.; Bingham, J.; Cox, D.; Passmore, J.A.; Williamson, A.L. Immunogenicity of a recombinant lumpy skin disease virus (neethling vaccine strain) expressing the rabies virus glycoprotein in cattle. Vaccine 2002, 20, 2693-2701. [CrossRef]

18. Wallace, D.B.; Mather, A.; Kara, P.D.; Naicker, L.; Mokoena, N.B.; Pretorius, A.; Nefefe, T.; Thema, N.; Babiuk, S. Protection of cattle elicited using a bivalent lumpy skin disease virus-vectored recombinant rift valley fever vaccine. Front. Vet. Sci. 2020, 7, 256. [CrossRef]

19. Aspden, K.; Passmore, J.A.; Tiedt, F.; Williamson, A.L. Evaluation of lumpy skin disease virus, a capripoxvirus, as a replicationdeficient vaccine vector. J. Gen. Virol. 2003, 84, 1985-1996. [CrossRef]

20. Liu, F.; Zhang, H.; Liu, W. Construction of recombinant capripoxviruses as vaccine vectors for delivering foreign antigens: Methodology and application. Comp. Immunol. Microbiol. Infect. Dis. 2019, 65, 181-188. [CrossRef]

21. Rhazi, H.; Safini, N.; Mikou, K.; Alhyane, M.; Lenk, M.; Tadlaoui, K.O.; Elharrak, M. Comparative sensitivity study of primary cells, vero, OA3.Ts and ESH-L cell lines to lumpy skin disease, sheeppox, and goatpox viruses detection and growth. J. Virol. Methods 2021, 293, 114164. [CrossRef]

22. Fay, P.C.; Cook, C.G.; Wijesiriwardana, N.; Tore, G.; Comtet, L.; Carpentier, A.; Shih, B.; Freimanis, G.; Haga, I.R.; Beard, P.M. Madin-Darby bovine kidney (MDBK) cells are a suitable cell line for the propagation and study of the bovine poxvirus lumpy skin disease virus. J. Virol. Methods 2020, 285, 113943. [CrossRef] [PubMed]

23. Munyanduki, H.; Omar, R.; Douglass, N.; Williamson, A.L. Removal of bovine viral diarrhea virus (BVDV) from lumpy skin disease virus (LSDV) vaccine stocks by passage on chorioallantoic membranes of fertilized hens' eggs. J. Virol. Methods 2020, 275, 113752. [CrossRef] [PubMed]

24. Soday, L.; Lu, Y.; Albarnaz, J.D.; Davies, C.T.R.; Antrobus, R.; Smith, G.L.; Weekes, M.P. Quantitative temporal proteomic analysis of vaccinia virus infection reveals regulation of histone deacetylases by an interferon antagonist. Cell Rep. 2019, 27, 1920-1933. [CrossRef]

25. Lu, Y.; Stuart, J.H.; Talbot-Cooper, C.; Agrawal-Singh, S.; Huntly, B.; Smid, A.I.; Snowden, J.S.; Dupont, L.; Smith, G.L. Histone deacetylase 4 promotes type I interferon signaling, restricts DNA viruses, and is degraded via vaccinia virus protein C6. Proc. Natl. Acad. Sci. USA 2019, 116, 11997-12006. [CrossRef] [PubMed]

26. Meyer, H.; Sutter, G.; Mayr, A. Mapping of deletions in the genome of the highly attenuated vaccinia virus MVA and their influence on virulence. J. Gen. Virol. 1991, 72, 1031-1038. [CrossRef]

27. Staib, C.; Drexler, I.; Ohlmann, M.; Wintersperger, S.; Erfle, V.; Sutter, G. Transient host range selection for genetic engineering of modified vaccinia virus Ankara. Biotechniques 2000, 28, 1137-1142, 1144-1146, 1148. [CrossRef]

28. Willis, K.L.; Langland, J.O.; Shisler, J.L. Viral double-stranded RNAs from vaccinia virus early or intermediate gene transcripts possess PKR activating function, resulting in NF-kappaB activation, when the K1 protein is absent or mutated. J. Biol. Chem. 2011, 286, 7765-7778. [CrossRef]

29. Shisler, J.L.; Jin, X.L. The vaccinia virus K1L gene product inhibits host NF-kappaB activation by preventing IkappaBalpha degradation. J. Virol. 2004, 78, 3553-3560. [CrossRef]

30. Bravo Cruz, A.G.; Han, A.; Roy, E.J.; Guzman, A.B.; Miller, R.J.; Driskell, E.A.; O’Brien, W.D., Jr.; Shisler, J.L. Deletion of the K1L gene results in a vaccinia virus that is less pathogenic due to muted innate immune responses, yet still elicits protective immunity. J. Virol. 2017, 91, e00542-17. [CrossRef]

31. Sutter, G.; Ramsey-Ewing, A.; Rosales, R.; Moss, B. Stable expression of the vaccinia virus K1L gene in rabbit cells complements the host range defect of a vaccinia virus mutant. J. Virol. 1994, 68, 4109-4116. [CrossRef]

32. Tulman, E.R.; Afonso, C.L.; Lu, Z.; Zsak, L.; Kutish, G.F.; Rock, D.L. Genome of lumpy skin disease virus. J. Virol. 2001, 75, 7122-7130. [CrossRef]

33. Tanzer, F.L.; Shephard, E.G.; Palmer, K.E.; Burger, M.; Williamson, A.L.; Rybicki, E.P. The porcine circovirus type 1 capsid gene promoter improves antigen expression and immunogenicity in a HIV-1 plasmid vaccine. Virol. J. 2011, 8, 51. [CrossRef]

34. Douglass, N.; Munyanduki, H.; Omar, R.; Gers, S.; Mutowembwa, P.; Heath, L.; Williamson, A.L. Influence of the Viral Superoxide Dismutase (SOD) Homologue on Lumpy Skin Disease Virus (LSDV) Growth, Histopathology and Pathogenicity. Vaccines 2020, 8 , 664. [CrossRef] [PubMed]

35. van Diepen, M.T.; Chapman, R.; Douglass, N.; Galant, S.; Moore, P.L.; Margolin, E.; Ximba, P.; Morris, L.; Rybicki, E.P.; Williamson, A.L. Prime-boost immunizations with DNA, modified vaccinia virus ankara, and protein-based vaccines elicit robust HIV-1 Tier 2 neutralizing antibodies against the CAP256 superinfecting virus. J. Virol. 2019, 93, e02155-18. [CrossRef] [PubMed]

36. Chakrabarti, S.; Sisler, J.R.; Moss, B. Compact, synthetic, vaccinia virus early/late promoter for protein expression. Biotechniques 1997, 23, 1094-1097. [CrossRef]

37. Di Pilato, M.; Mejias-Perez, E.; Gomez, C.E.; Perdiguero, B.; Sorzano, C.O.; Esteban, M. New vaccinia virus promoter as a potential candidate for future vaccines. J. Gen. Virol. 2013, 94, 2771-2776. [CrossRef]

38. Omar, R. Comparison of the Two Lumpy Skin Disease Virus Vaccines, Neethling and Herbivac, and Construction of a Recombinant Herbivac-Rift Valley Fever Virus Vaccine. Master's dgree, University of Cape Town, Cape Town, South Africa, 2015.

39. Kumar, S.; Boyle, D.B. A poxvirus bidirectional promoter element with early/late and late functions. Virology 1990, 179, 151-158. [CrossRef] 
40. Cochran, M.A.; Puckett, C.; Moss, B. In vitro mutagenesis of the promoter region for a vaccinia virus gene: Evidence for tandem early and late regulatory signals. J. Virol. 1985, 54, 30-37. [CrossRef] [PubMed]

41. Wyatt, L.S.; Shors, S.T.; Murphy, B.R.; Moss, B. Development of a replication-deficient recombinant vaccinia virus vaccine effective against parainfluenza virus 3 infection in an animal model. Vaccine 1996, 14, 1451-1458. [CrossRef]

42. Alharbi, N.K. Poxviral promoters for improving the immunogenicity of MVA delivered vaccines. Hum. Vaccin Immunother 2019, 15, 203-209. [CrossRef]

43. Moss, B. Reflections on the early development of poxvirus vectors. Vaccine 2013, 31, 4220-4222. [CrossRef]

44. Okeke, M.I.; Okoli, A.S.; Diaz, D.; Offor, C.; Oludotun, T.G.; Tryland, M.; Bohn, T.; Moens, U. Hazard characterization of modified vaccinia virus ankara vector: What are the knowledge gaps? Viruses 2017, 9, 318. [CrossRef]

45. Pinschewer, D.D. Virally vectored vaccine delivery: Medical needs, mechanisms, advantages and challenges. Swiss Med. Wkly. 2017, 147, w14465. [CrossRef]

46. Prow, N.A.; Jimenez Martinez, R.; Hayball, J.D.; Howley, P.M.; Suhrbier, A. Poxvirus-based vector systems and the potential for multi-valent and multi-pathogen vaccines. Expert Rev. Vaccines 2018, 17, 925-934. [CrossRef] [PubMed]

47. Offerman, K.; Deffur, A.; Carulei, O.; Wilkinson, R.; Douglass, N.; Williamson, A.L. Six host-range restricted poxviruses from three genera induce distinct gene expression profiles in an in vivo mouse model. BMC Genomics 2015, 16, 510. [CrossRef] [PubMed]

48. Yates, N.L.; Liao, H.X.; Fong, Y.; deCamp, A.; Vandergrift, N.A.; Williams, W.T.; Alam, S.M.; Ferrari, G.; Yang, Z.Y.; Seaton, K.E.; et al. Vaccine-induced Env V1-V2 IgG3 correlates with lower HIV-1 infection risk and declines soon after vaccination. Sci Transl. Med. 2014, 6, 228ra239. [CrossRef] [PubMed]

49. Cottingham, M.G.; Carroll, M.W. Recombinant MVA vaccines: Dispelling the myths. Vaccine 2013, 31, 4247-4251. [CrossRef]

50. Burgers, W.A.; Shephard, E.; Monroe, J.E.; Greenhalgh, T.; Binder, A.; Hurter, E.; Van Harmelen, J.H.; Williamson, C.; Williamson, A.L. Construction, characterization, and immunogenicity of a multigene modified vaccinia Ankara (MVA) vaccine based on HIV type 1 subtype C. AIDS Res. Hum. Retrovir. 2008, 24, 195-206. [CrossRef]

51. Di Pilato, M.; Sanchez-Sampedro, L.; Mejias-Perez, E.; Sorzano, C.O.S.; Esteban, M. Modification of promoter spacer length in vaccinia virus as a strategy to control the antigen expression. J. Gen. Virol. 2015, 96, 2360-2371. [CrossRef]

52. Noyce, R.S.; Lederman, S.; Evans, D.H. Construction of an infectious horsepox virus vaccine from chemically synthesized DNA fragments. PLoS ONE 2018, 13, e0188453. [CrossRef] [PubMed]

53. Gowripalan, A.; Smith, S.; Stefanovic, T.; Tscharke, D.C. Rapid poxvirus engineering using CRISPR/Cas9 as a selection tool. Commun. Biol. 2020, 3, 643. [CrossRef] [PubMed]

54. Wyatt, L.S.; Carroll, M.W.; Czerny, C.P.; Merchlinsky, M.; Sisler, J.R.; Moss, B. Marker rescue of the host range restriction defects of modified vaccinia virus Ankara. Virology 1998, 251, 334-342. [CrossRef] [PubMed] 